\begin{tabular}{|c|c|c|}
\hline Case Reports in & \multicolumn{2}{|c|}{ Case Rep Gastroenterol 2018;12:396-401 } \\
\hline Gastroenterology & $\begin{array}{l}\text { DOI: 10.1159/000490522 } \\
\text { Published online: August 21, } 2018\end{array}$ & $\begin{array}{l}\text { @ } 2018 \text { The Author(s) } \\
\text { Published by S. Karger AG, Basel } \\
\text { www.karger.com/crg }\end{array}$ \\
\hline & $\begin{array}{l}\text { This article is licensed under the } \\
\text { International License (CC BY-NC) } \\
\text { Usage and distribution for commer }\end{array}$ & $\begin{array}{l}\text { nons Attribution-NonCommerc } \\
\text { ger.com/Services/OpenAccessLi } \\
\text { uires written permission. }\end{array}$ \\
\hline
\end{tabular}

\title{
Primary Mesenteric Carcinoid Tumor Presenting with Carcinoid Syndrome
}

\author{
Oluwaseun Shogbesan $^{a} \quad$ Abdullateef Abdulkareem $^{a} \quad$ Binu Pappachen ${ }^{b}$ \\ John Altomare ${ }^{c}$ \\ aDepartment of Internal Medicine, Tower Health System, West Reading, PA, USA; \\ ${ }^{b}$ Hospitalist Services, Department of Medicine, Tower Health System, West \\ Reading, PA, USA; 'Digestive Disease Associates, Wyomissing, PA, USA
}

\section{Keywords}

Carcinoid syndrome $\cdot$ Diarrhea $\cdot$ Mesenteric carcinoid $\cdot$ Tumor

\begin{abstract}
Neuroendocrine neoplasms (NENs) are a diverse group of tumors arising throughout the body with a common origin from neuroendocrine cells. Well-differentiated NENs, also known as neuroendocrine tumors (NETs), are generally indolent and are often found incidentally, while poorly differentiated tumors are more aggressive. Carcinoid tumors are NETs arising from the gastrointestinal tract and less commonly from the lungs, thymus, and kidneys. NETs in the mesentery arise from metastasis from primary tumor, and carcinoid syndrome in this setting results from concomitant metastasis to the liver. Primary mesenteric carcinoid tumors are very rare. We present a 64-year-old man with carcinoid syndrome from a mesenteric carcinoid tumor without evidence of liver metastasis or other primary tumor sites.
\end{abstract}

(C) 2018 The Author(s)

Published by S. Karger AG, Basel

\section{Introduction}

Neuroendocrine neoplasms (NENs) encompass diverse types of tumors arising from neuroendocrine (enterochromaffin) cells found throughout the body. Although arising from 
different organs, these tumors have certain characteristics in common. Of note, NENs have a potential to secrete bioactive substances into the bloodstream.

Classification of NENs is complex and the nomenclature is ever evolving. Broadly, NENs are classified based on tumor differentiation into well-differentiated (low and intermediate grade) neuroendocrine tumors (NETs) and poorly differentiated (high grade) neuroendocrine carcinomas [1]. Grading addresses aggressiveness of the tumor, with grade 1, 2, and 3 representing low, intermediate, and poorly differentiated tumors, respectively [2]. Well-differentiated NETs are generally rare [1]. Carcinoid tumors are well-differentiated NETs arising commonly from the digestive tract (90\%) [3]. Carcinoid tumors account for about $2 \%$ of all gastrointestinal tumors [4]. Gastrointestinal carcinoid tumors are classified based on embryonic origin into foregut, midgut, and hindgut carcinoid tumors, with over $50 \%$ arising from the midgut, particularly the small intestine [5, 6]. Other non-gastrointestinal tract carcinoid tumor origins include the lungs, thymus, ovaries, and kidneys.

While well-differentiated NETs often have a relatively indolent course, there is a propensity for metastasis to the liver producing the classic carcinoid syndrome of diarrhea and flushing. Metastasis to other sites such as the peritoneum and mesentery is also common [5, 7]. Midgut carcinoid tumors commonly spread to the mesentery; however, primary mesenteric NETs are very rare [8]. We present a 64-year-old man with a mesenteric NET without any other primary site.

\section{Case Presentation}

A 64-year-old man with a past medical history of mechanical aortic valve replacement, on Coumadin, with coronary artery disease and a history of coronary artery bypass graft, permanent atrial fibrillation, gastrointestinal bleeding secondary to arteriovenous malformation, diabetes mellitus, and ambulatory dysfunction was brought to the emergency department for progressively worsening generalized weakness, passage of watery nonbloody stool of 5 weeks' duration, and dark stools of 5 days' duration. The patient had not seen a physician in over 2 years and reported minimal ambulation in the past 2 years. He endorsed a 40 -pound unintentional weight loss over 2 years and use of NSAIDs for arthritis, but was unable to quantify NSAID use.

Vital signs showed a blood pressure of $88 / 48 \mathrm{~mm} \mathrm{Hg}$, a pulse rate of 92 beats per minute, and a respiratory rate of 23 cycles per minute with normal pulse oximetry on room air. The patient was noted to be frail, cachectic, pale, and unkempt. He also had diffuse excoriation marks with areas of open wounds over the buttocks, abdomen, and legs. He was also noted to be soiled with copious amount of feces. On auscultation, the patient had an audible click consistent with known mechanical valve; the rest of the physical examination was unremarkable. Laboratory data were remarkable for significant anemia with hemoglobin of $5.9 \mathrm{~g} / \mathrm{dL}$ (3 years prior: $11.7 \mathrm{~g} / \mathrm{dL}$; normal: $14.0-17.5 \mathrm{~g} / \mathrm{dL}$ ), leukocytosis with a WBC of $24,000 / \mu \mathrm{L}$, and thrombocytosis of $722,000 / \mu \mathrm{L}$. Iron deficiency was also noted (mean corpuscular volume $77.8 \mathrm{fL}$, ferritin $25 \mathrm{ng} / \mathrm{mL}$, iron $<10 \mu \mathrm{g} / \mathrm{dL}$, TIBC $251.25 \mu \mathrm{g} / \mathrm{dL}$ ). Electrolyte and hepatic panel revealed creatinine $2.4 \mathrm{mg} / \mathrm{dL}$ (normal: 0.6-1.3 mg/dL), BUN $75 \mathrm{mg} / \mathrm{dL}$ (normal: 7-25 mg/dL), low glucose of $54 \mathrm{mg} / \mathrm{dL}$, low albumin of $2.3 \mathrm{~g} / \mathrm{dL}$ (normal: 3.5-5.7 g/dL), low total bilirubin of $0.2 \mathrm{mg} / \mathrm{dL}$ (normal: $0.3-1.1 \mathrm{mg} / \mathrm{dL}$ ), ALT of $3 \mathrm{IU} / \mathrm{L}$ (normal: 7-52 IU/L), and AST of $13 \mathrm{IU} / \mathrm{L}$ (normal: 13-39 IU/L). Stool studies were negative for all tested pathogens including Clostridium difficile. Stool was positive for occult blood on admission. The international normalized ratio was markedly elevated to 13.1 with a prothrombin time of $99.8 \mathrm{~s}$ and was reversed with 


\section{Case Reports in Gastroenterology}

Case Rep Gastroenterol 2018;12:396-401

DOI: $10.1159 / 000490522$

(c) 2018 The Author(s). Published by S. Karger AG, Basel www.karger.com/crg

Shogbesan et al.: Primary Mesenteric Carcinoid Tumor Presenting with Carcinoid Syndrome

four-factor prothrombin complex concentrate in addition to blood transfusion. Magnetic resonance imaging of the left leg showed segmental focus of osteomyelitis with blood culture growing Proteus mirabilis for which the patient was started on antibiotics.

During evaluation at the emergency department, a prior computed tomography scan from 7 years prior showing a $2.3 \times 2.3 \mathrm{~cm}$ minimally lobulated minimally calcified mesenteric nodule in the right mid to lower quadrant was noted. A repeat computed tomography was obtained which showed an interval enlargement to $2.7 \times 2.6 \mathrm{~cm}$ (Fig. 1). The patient had been lost to follow-up for his mesenteric mass. He subsequently underwent esophagogastroduodenoscopy during index admission with findings of few small fundic gland polyps with negative biopsies for celiac disease. A colonoscopy to localize the source of gastrointestinal bleeding showed moderate left colon diverticulosis and small internal hemorrhoids with no active bleeding.

A fecal management system had been placed prior to colonoscopy preparation given the patient's debilitated status and limited mobility, and the patient was noted to have copious watery, nonbloody diarrhea during the hospital stay. He also had recurrent erythematous pruritic rashes over the face and trunk initially felt to be a drug rash, but the rash did not improve with change of antibiotics. Further workup for chronic diarrhea, including a flexible sigmoidoscopy, was done to obtain biopsies for microscopic colitis, which was negative. Tropheryma whipplei PCR was also negative. Given the chronic diarrhea and the mesenteric mass, carcinoid syndrome was suspected. The chromogranin A level was elevated at 9,340 ng/mL (normal: 0-95 ng/mL), and 24-h urine collection for 5-hydroxyindoleacetic acid (5-HIAA) showed a 5-HIAA urine-creatinine ratio of $25 \mathrm{mg} / \mathrm{g}$ (normal: 0-14 mg/g). These findings were suggestive of a NET possibly originating from the small bowel with possible mesenteric metastasis. A magnetic resonance enterography done for tumor localization revealed the known solitary mesenteric mass without additional findings of tumors elsewhere (Fig. 2). The patient then underwent computed tomography-guided core biopsy of the mesenteric mass which was immunohistochemically reactive for synaptophysin, chromogranin, and CD56. Ki-67 labelling index and mitotic rate were both $<1 \%$, consistent with a well-differentiated, low-grade NET (carcinoid tumor). An octreotide scan showed focal radiotracer accumulation within the previously biopsied mesenteric mass with no other sites of abnormal tracer activity. Echocardiography showed a normally functioning mechanical aortic valve with mild tricuspid regurgitation.

The patient was started on octreotide and evaluated for surgical removal of the mass, but he was deemed a poor surgical candidate given multiple comorbidities and poor baseline functional status. After further discussions with the patient and his family, a decision of transition to comfort-focused care was made. He was discharged on hospital day 35 after initial presentation and died within a few days of discharge.

\section{Discussion}

Primary mesenteric carcinoid tumors are extremely rare [8]. Park et al. [9] reported a case of a solitary 8-cm mesenteric carcinoid tumor in a 73-year-old woman after a meticulous search for tumors at other sites. Yamanuha et al. [10] reported a mesenteric tumor in a 52-year-old with a partially calcified lobulated mass in the mesentery, with smaller nodes in the adjacent mesentery, also without tumor activity elsewhere after imaging, colonoscopy, and direct visualization at surgery. Karahan et al. [8] also reported a 2-cm primary mesenteric tumor with an area of calcification. 
Our patient underwent imaging without contrast given kidney dysfunction, and it is conceivable that a small occult primary tumor or micro hepatic metastasis was missed; however, an indium-111 pentetreotide scanning (OctreoScan) did not reveal uptake at any other site, making this less likely. While it is possible that these reported mesenteric carcinoid tumors, including our index case, arose from an occult primary, there are neuroendocrine cells in the mesenteric vessels, hence the possibility of NETs arising primarily from the mesentery.

Given their indolent nature, carcinoid tumors are often found incidentally on imaging or during screening colonoscopy or due to symptoms related to tumor secretion or tumor growth. Carcinoid syndrome is characterized by chronic diarrhea and/or flushing results from tumor secretion of serotonin and other bioactive amines and peptides into the systemic circulation. This is typically seen with metastasis of midgut tumors to the liver [6]. A recent Surveillance, Epidemiology, and End Results (SEER) database study of over 9,000 NET patients found the presence of carcinoid syndrome in 19\% of NETs at diagnosis [11]. The study also noted carcinoid syndrome resulting from atypical tumors such as tumors located in the colorectum in the absence of detectable hepatic metastasis [11]. The authors raised the question of the contribution of undetectable hepatic metastasis. While carcinoid syndrome is more common in advanced metastatic disease, a surprisingly high number of patients with local disease (19\%) and regional disease (39\%) had carcinoid syndrome in the SEER database [11]. Our patient had local mesenteric carcinoid and presented with persistent diarrhea and intermittent erythematous rash which was initially thought to be related to a drug reaction but was likely atypical flushing. While the classic flush lasts 20-30 s and involves the face, neck, and chest with mild burning, pruritic and well-demarcated patchy rash lasting hours to days has been reported with carcinoid syndrome [12].

The diagnosis of carcinoid syndrome is done by demonstrating the presence of secreted substances by measuring chromogranin A and quantifying urinary excretion of 5-HIAA. Imaging modalities, including multiphasic contrast-enhanced computed tomography scan and magnetic resonance imaging, are recommended for tumor localization and staging. OctreoScan (indium-111 pentetreotide) is helpful for well-differentiated NETs, given high levels of somatostatin receptors on carcinoid tumors, and helpful to predict response to somatostatin analogs. Newer functional PET scans have the advantage of increased sensitivity for detecting small lesions.

\section{Statement of Ethics}

The authors have no ethical conflicts to disclose.

\section{Disclosure Statement}

The authors declare no conflict of interest regarding the publication of this paper.

\section{References}

1 Klimstra DS, Modlin IR, Coppola D, Lloyd RV, Suster S. The pathologic classification of neuroendocrine tumors: a review of nomenclature, grading, and staging systems. Pancreas. 2010 Aug;39(6):707-12.

2 Rindi G, Klöppel G, Couvelard A, Komminoth P, Körner M, Lopes JM, et al. TNM staging of midgut and hindgut (neuro)endocrine tumors: a consensus proposal including a grading system. Virchows Arch. 2007 Oct;451(4):757-62. 


\section{Gastroenterology}

\begin{tabular}{l|l}
\hline DOI: 10.1159/000490522 & (c) 2018 The Author(s). Published by S. Karger AG, Basel
\end{tabular}
www.karger.com/crg

Shogbesan et al.: Primary Mesenteric Carcinoid Tumor Presenting with Carcinoid Syndrome

3 Modlin IM, Lye KD, Kidd M. A 5-decade analysis of 13,715 carcinoid tumors. Cancer. 2003 Feb;97(4):934-59.

4 Horton KM, Kamel I, Hofmann L, Fishman EK. Carcinoid tumors of the small bowel: a multitechnique imaging approach. AJR Am J Roentgenol. 2004 Mar;182(3):559-67.

5 Woodside KJ, Townsend CM Jr, Mark Evers B. Current management of gastrointestinal carcinoid tumors. J Gastrointest Surg. 2004 Sep-Oct;8(6):742-56.

6 Modlin IM, Kidd M, Latich I, Zikusoka MN, Shapiro MD. Current status of gastrointestinal carcinoids. Gastroenterology. 2005 May;128(6):1717-51.

7 Akerström G, Hellman P, Hessman 0, Osmak L. Management of midgut carcinoids. J Surg Oncol. 2005 Mar;89(3):161-9.

8 Karahan OI, Kahriman G, Yikilmaz A, Ozkan M, Bayram F. Gastrointestinal carcinoid tumors in rare locations: imaging findings. Clin Imaging. 2006 Jul-Aug;30(4):278-82.

9 Park IS, Kye BH, Kim HS, Kim HJ, Cho HM, Yoo C, et al. Primary mesenteric carcinoid tumor. J Korean Surg Soc. 2013 Feb;84(2):114-7.

10 Yamanuha J, Ballinger R, Coon D, Navin J. Carcinoid tumor presenting as a primary mesenteric mass: a case report and review of the literature. Hawaii Med J. 2009 Jul;68(6):137-9.

11 Halperin DM, Shen C, Dasari A, Xu Y, Chu Y, Zhou S, Shih YT, Yao JC: Frequency of carcinoid syndrome at neuroendocrine tumour diagnosis: a population-based study. Lancet Oncol. 2017;18:525-34.

12 Jabbour SA, Davidovici BB, Wolf R. Rare syndromes. Clin Dermatol. 2006 Jul-Aug;24(4):299-316.

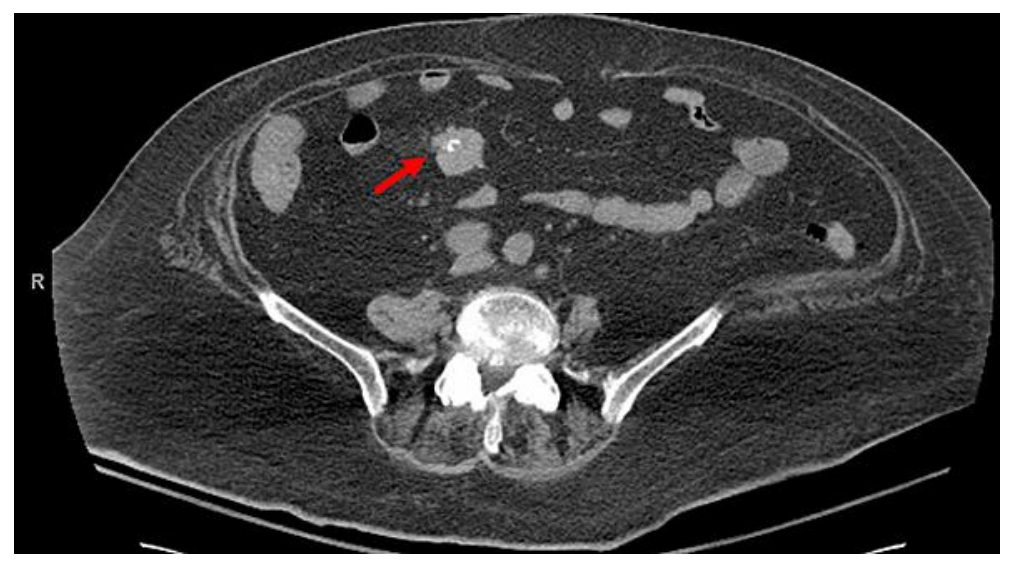

Fig. 1. Axial computed tomography of the abdomen showing mesenteric carcinoid tumor with central calcification (arrow). 


\begin{tabular}{|c|c|c|}
\hline \multirow{2}{*}{$\begin{array}{l}\text { Case Reports in } \\
\text { Gastroenterology }\end{array}$} & \multicolumn{2}{|c|}{ Case Rep Gastroenterol 2018;12:396-401 } \\
\hline & DOI: $10.1159 / 000490522$ & $\begin{array}{l}\text { O } 2018 \text { The Author(s). Published by S. Karger AG, Basel } \\
\text { www.karger.com/crg }\end{array}$ \\
\hline
\end{tabular}

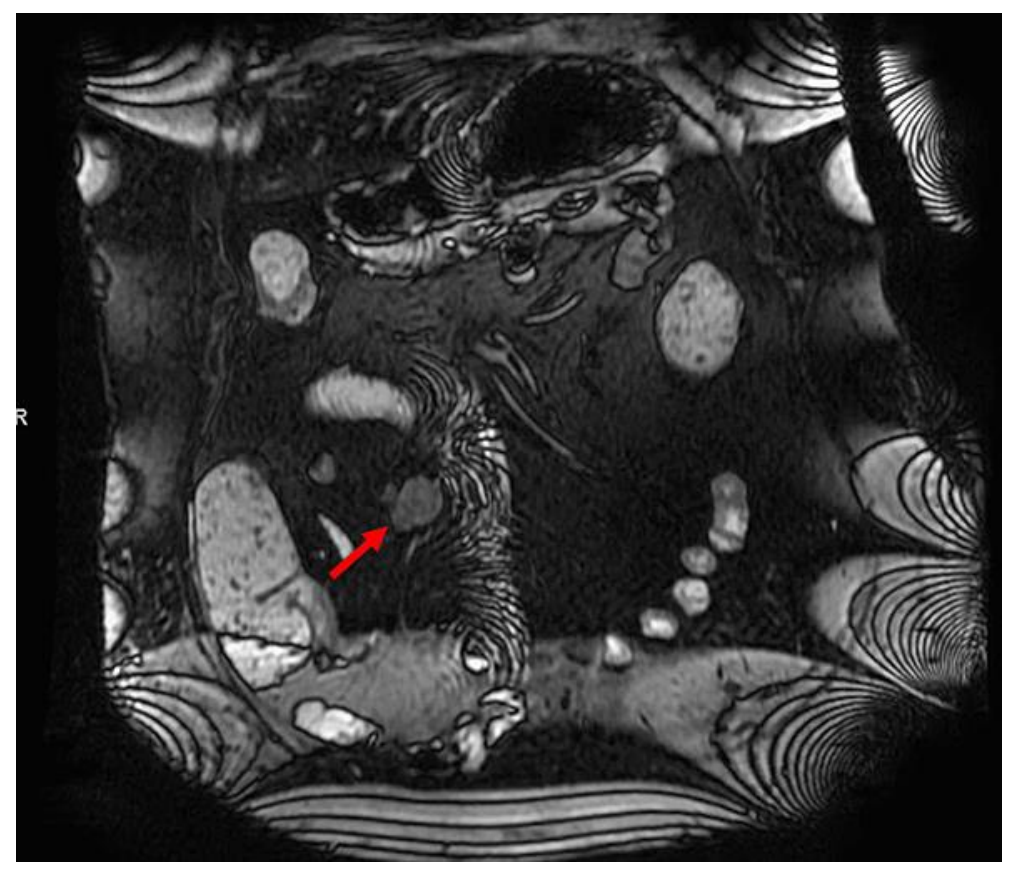

Fig. 2. Coronal noncontrast magnetic resonance enterography with the arrow showing the mesenteric tumor. 